\title{
Osteomyelitis infection disguised as Reiter's Syndrome in a child: A
}

case report

Nnennaya Opara ${ }^{1}$

${ }^{1}$ Charleston Area Medical Center Health System Inc

December 2, 2021

\section{Abstract}

This is a case of a 16-year-old African boy with Osteomyelitis presenting with symptoms of reactive arthritis (Reiter's syndrome) KEYWORDS Osteomyelitis, Reiter's syndrome, Fever, Bone pain, Erythema, Ewing sarcoma

\section{Hosted file}

osteomyelitis case report.docx available at https://authorea.com/users/449166/articles/ 547758-osteomyelitis-infection-disguised-as-reiter-s-syndrome-in-a-child-a-case-report

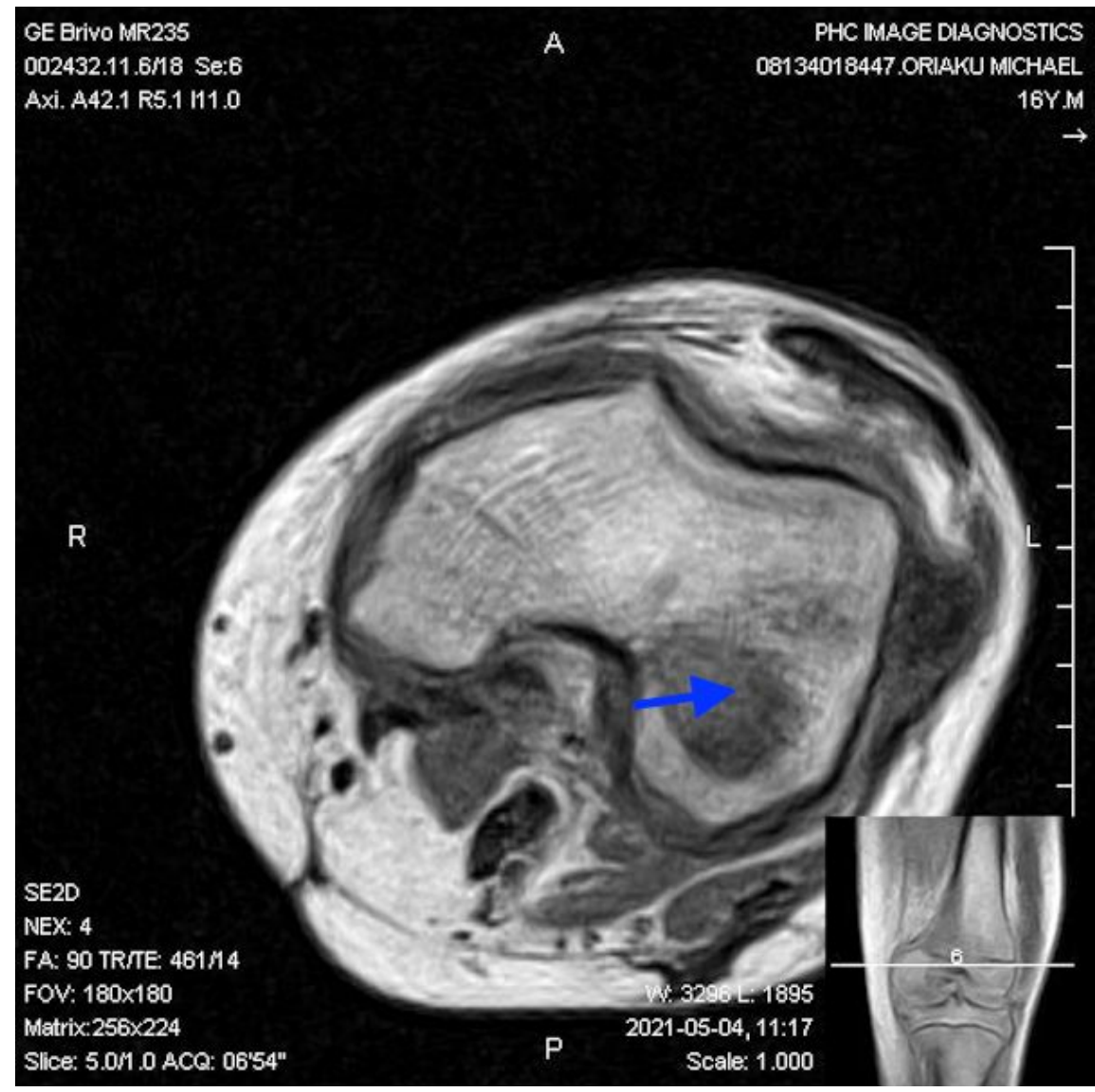




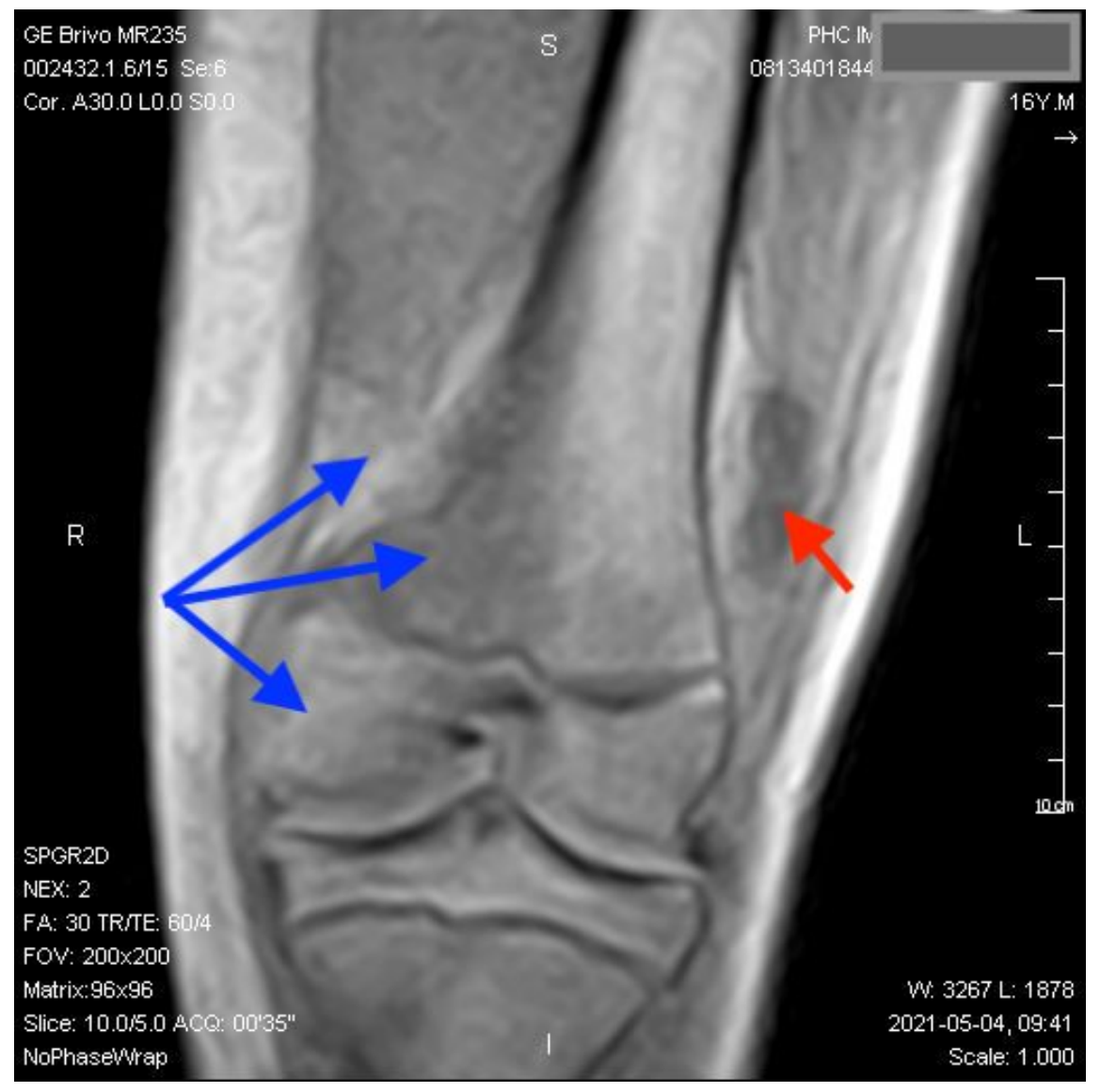

